Laboratorio de Arte,1-1988 http://dx.doi.org/10.12795/LA.1988.i01.02

\title{
LOS RECINTOS AMURALLADOS Y EL URBANISMO EN COGOLLUDO DE 1176 A 1505
}

Teresa Laguna Paúl y Antonio J. López Gutiérrez

\section{La villa de Cogolludo desde sus orígenes hasta los Medinaceli}

El origen de la villa de Cogolludo hay que vincularlo a la fortaleza situada en la cumbre de un cerro entre los ríos Sorbe, Borvona y Aliendre, afluentes del Henares, y en cuya plataforma se realizarían las acampadas militares o pastoriles que debieron constituir el inicio del asentamiento urbano. Algunos autores piensan que esta fortaleza es de origen árabe (1), aunque las primeras noticias documentales de Cogolludo se remontan al año 1058 en época de Alfonso VI; monarca que quince años más tarde donó la villa al monasterio de San Pedro Gumiel (2). Sin embargo, no es hasta un siglo más tarde cuando este lugar comenzará a tener cierta importancia. Alfonso VIII donó la villa a la Orden de Calatrava en 1176 y sin duda es a partir de esta época cuando se amplió la antigua fortaleza en el castillo roquero, que con modificaciones posteriores, ha llegado hasta nuestros días.

La planta del castillo está determinada por la orografía del terreno: sus seis torres macizas de mampostería y sección semicircular están colocadas en círculo mirando hacia el barranco de San Agustín y el arroyo de Arbancón. En

\footnotetext{
El estudio histórico-artístico corre a cargo de T. Laguna Paúl, las notas paleográficas y diplomáticas han sido realizadas así como la transcripción de los documentos por A.J. López Gutiérrez.

1.-LAYNA SERRANO; Fco.: Castillos de Guadalajara, Madrid, Nuevas Gráficas, 1933, pp. 94.

PAVON MALDONADO, B: Guadalajara, Medieval. Are y Arqueologla árabe y mudejar, Madrid, Inst. M. Asín, 1984, pp 11 y ss. (Guadalajara Medieval).

2.-CATALINA GARCIA, J.: Relaciones topográficas de Guadalajara en "Memorial Histórico Español" XLII (1903) pp. 14-15 (Relaciones) LOPEZ GUTIERREZ, A.J.: Documentación Señorial y Concejil del Sehorlo de Cogolludo en el Archivo Ducal de Medinaceli en "Historia, Instituciones y Documentos" 10 (1984) p. 4 (Documentación Sefrorialy Concejil).
} 
el frente que mira al pueblo está la torre del homenaje con planta cuadrada y muros de mampostería encintada que tenía dos cámaras abovedadas, de las que se conserva la inferior. Todo ello lleva a pensar en una ampliación mudéjar realizada a fines del siglo XII (3), o principios del siguiente, que coincide con la donación a la Orden de Calatrava.

Años más tarde, en 1242, el gran Maestre de esta Orden concedió al concejo de Cogolludo el fuero de Guadalajara. La autonomía jurídica que este documento conlleva (4) nos hace suponer que no fue después de esta fecha cuando se hicieron las primeras murallas y desde este momento nos encontramos con una ciudad tal y como se contempla en las Partidas de Alfonso X (5). Esta primera cerca y castillo estaban muy deteriorados en 1355 cuando fray Garci López, a la razón Maestre de la Orden, otorgó la villa a Iñigo López de Orozco, quien se comprometió a reparar en ella todos los lugares que fuesen necesarios por indicación de los otorgantes (6).

Durante estos siglos el asentamiento urbano se consolidó en las faldas del castillo dando lugar a tres calles principales llamadas de San Pedro, del Val y Juan Mingo que serían las que establecerían la comunicación entre las puertas de la ciudad y originariamente pudieron coincidir con los antiguos caminos de ganado. La muralla levantada por la Orden de Calatrava y reparada por Iñigo López de Orozco partiría, posiblemente, del castillo y rodearía todo el núcleo habitado cerrándose al este por las calles de Palacio, Sareado y Moderna, al norte por la llamada plaza de la Farola o la calle del Caño y hacia occidente uniría con el castillo al cual se subía por la calle de la Estrella. Las

3.-PABON MALDONADO, B:: Guadalajara Medieval, p. 117-119.

4.-A propósito de la importancia de la concesión de un fuero a las ciudades Vid. CARANDE TOVAR, R.: Sevilla, Fortaleza y mercado, Sevilla, Servicio de publicaciónes de la Universidad, 1972, pp 20 y ss.

5.-Las fuentes legales alfonsies justifican la denominación de ciudad del siguiente modo: "Ciudad que se entiende todo aquel lugar que es creado de muros, en los arrauales, e con los edificios que se tienen con ello". Vid. Partida (P) 7,33,6; otros aspectos pueden verse en P.2.20.8; P.3.32.20; P.3.32.22; Espéculo (E); 2.9.P; E .5.8.3. Las Siete Partidas del Rey Don Altonso el Sabio, cotejadas con varios códices antiguos (Madrid, Real Academia de la Historia, 1807), Madrid Ed. Atlas, 1972, 3 vols.

6.-ACADEMIA DE LA HISTORIA (A.H.) Colección Salazar y Castro, 1-39 (Doc. $n^{\circ}$ 1); fols 86r. en el que se recoge: "El castiello e villa nuestro de Cogolludo a mucho menester de reparar a adobar... otrosi que faredes labrar la dicha villa e castiello e reparar en todos los lugares en todos los lugares que cumpliere e menester obiere..." "e otrogo de labrar e de reparar en todos los lugares que cumpliere e menester obiere...". Este mismo espiritu queda recogido en las fuentes legales alfonsies: "Como los castillos, e los muros delas villas, e las otras fortalezas, con las calçadas, e las fuentes, e los caños, se deuen mantener, e reparar" Vid. P.3.32,20. 
puertas de esta cerca estaban situadas, aproximadamente, al suroeste entre la calle del Comercio y el ayuntamiento o en el inicio de la calle de la Estrella con la de Juan Mingo, por ella penetrarían los viajeros procedentes de Guadalajara que tras pasar por la calle de San Pedro y. sortear la iglesia continuarían su marcha hacia el norte rumbo a Soria y Segovia por el camino de Arbancón. En la zona de levante estaba situada la tercera puerta al final de la calle del Val en dirección hacia Jadraque y seguramente ubicada en la llamada plaza de la Fuente de Abajo. Topónimos como la Ronda del Médico y la calle de la Torre Mayor que aparecen en el plano de 1895 (7) nos indican indudablemente un ensanche de la ciudad llevado a cabo a fines del siglo XV (Lám. 1 y 2).

\section{Los cambios producidos en la fisonomía urbanística durante los Medinaceli.}

La vinculación de Cogolludo a la familia de los Medinaceli desde 1438 (8), y en especial al primogénito de esta casa trajo la prosperidad y engrandecimiento de esta villa alcarreña. Buena muestra de ello es el establecimiento de un mercado todos los miércoles según documento de 1461, el aumento demográfico y las mejoras constructivas llevadas a cabo, confirmadas por el testimonio de Antonio de Laling (9).

Luis de la Cerda y Mendoza, que heredó los dominios familiares en 1459, durante sus estancias en Cogolludo debió residir en el castillo hasta que a fines del siglo XV construyó un palacio en la parte baja de la ciudad. La obra, según hipótesis de D. Manuel Gómez Moreno, fue realizada por Lorenzo Vázquez de Segovia entre 1492 y 1495, fechas que coinciden con la boda de la hija de $\mathrm{D}$. Luis con el marqués de Cenete y la defunción de la misma. La relación entre D. Luis de la Cerda y Lorenzo Vázquez, arquitecto

7.-Este plano fue publicado por SANZ NUNEZ, A.C.: Cogolludo, la estructura urbana e "Boletín de SA.D.E.C.O." 4 (1984) p. 11, Corresponde al plano de Cogolludo levantado en 1895 y conservado en el instituto Geográfico Nacional.

8. ARCHNO DUCAL DE MEDINACELI (A.D.M.) Secc. Cogolludo, leg. 11, ne 36: Olmedo, 12 de septiembre de 1438: Carta de permuta entre Luis de la Cerda y Femán Alvarez de Toledo (Doc. $n^{2} 2$ ).

9. J. CATALINA GARCIA apunta que hacia 1581 contaba la villa con 600 vecinos, mientras que cuarenta ahos antes contaba entre 350 y 400 Vid.: Relaciones p. 6; LOPEZ GUTIERREZ "Documentación Sefiorial y Concejir, pp. 69-70. A. de LALING: Primer viaje de Felipe el Hermoso a España en 1501. En GARCIA MERCADAL, J. Viajes de Extranjeros por Espana y Portugal, Madrid, Aguilar, 1952" T.I. pg. 487. en 1501 nos dice: "이 miércoles el archiduque y su esposa estuvieron en Sadraque y fue monsehor a visitar un palacio situado en el mercado del pueblo llamado Cogolludo, perteneciente al duque de Medina, a tres leguas de Jadraque, que bien vale por siete de los nuestros, y es el más rico alojamiento de Espana". 
de la familia Mendoza, debió establecerse cuando el duque hipotecó su villa de Cogolludo como dote de su hija al casarse con el vástago del Gran Cardenal (10). Sin embargo, si el Palacio fue construido en estos tres años sigue siendo una hipótesis aún por corroborar pero que consideramos válida a tenor de la documentación que acerca de las obras realizadas en la muralla aportamos. La presencia de Lorenzo Vázquez como tasador de las obras efectuadas en el castillo por Juan de la Cerda, hijo del anterior, en 1503 avalan lo anteriormente dicho e indican la continuidad de este artista junto a otros maestros de cantería en las construcciones de este linaje.

A finales del siglo XV el caserío medieval de Cogolludo debía estar completamente rebasado y sus primeras murallas obsoletas. La planificación de su modernización en época de D. Luis de la Cerda y Mendoza no quedó sólo en el Palacio, sino que abarcó la remodelación urbana del sector posterior de éste y frente donde se ubicó la gran plaza, antes en las afueras de la ciudad, donde se llevaba a cabo el mercado a la vez que podía servir por sus grandes dimensiones para otros fines como justas o juegos. La ampliación de la villa necesitaba nuevas murallas cuya traza debió planificarse a la vez que el Palacio pero cuyo trazado cambió al menos en dos ocasiones.

La documentación del Archivo Ducal de Medinaceli, referente a esta muralla, comienza en 1496, pero su contenido indica ciertas tapias realizadas en 1494 y derribadas un año después para:

- ensanchar más la villa... desde la esquina de la huerta de faça la plaza fasta la torre de la coracha, a donde se a de façer, que es encima del lomo. (11).

En este sector suroccidental de la ciudad es precisamente donde está situado el Palacio y sufrirá otro cambio de trazado pagado en 1496:

para abaxar la puerta de Guadalajara a donde agora está, e porque vinieron los pannos derechos desde la puerta fasta la dicha puerta de Guadalajara... lo que se derribó desde la quadrilla de Garçía de Lievana (delante de la huerta) fasta la quadrilla de Juan Pérez, que es baxo la. puerta de San Sebastián (12).

En la documentación no se hace mención explícita al Palacio pero los términos "delante de la huerta", "detrás de la huerta" y "detrás de las casas

10.-GOMEZ MORENO, M.: SObre Renacimiento en Casilla. Notas para un estudio preliminar. 1. Hacia Lorenzo Váquez en "Archivo Espanol de Arte y Arqueologia" 1 (1925) 18-22 (A.E.A.A.).

11.-A.D.N. Sec. Cogolludo, leg. 11, $n^{2} 44$, fol. ír. (1495-1496) (Cogolludo). (Doc. $n^{0} 3$ ).

12. -Ctr. Doc. ne 3, fol. $4 \mathrm{v}$. 
nuevas de la plaza" creemos que son los que indican su situación y nos hacen deducir que la residencia estaba ya concluida en estas fechas cuando se hicieron las primeras obras de la muralla en 1494.

En la construcción de esta muralla se observan varios estados diferentes según los pagos efectuados el 11 de octubre de 1496. La muralla partía del castillo y por detrás de la iglesia de Santa María llegaba hasta el postigo de Arbancón. En este sector hay seis torres, completamente terminadas, y en él trabajan cinco cuadrillas que refuerzan el grosor de los taludes y seguramente elevan la altura de la muralla levantada por la Orden de Calatrava (13). A continuación de este postigo comienza la verdadera ampliación de la villa de los Medinaceli extendiéndose hacia mediodía y construyéndose dos puertas de entrada, que estaban muy avanzadas según el documento: la puerta de Medinaceli, al final de la calle moderna, y la de Jadraque en la prolongación de la calle del Carmen y trasladada de lugar con respecto a la muralla anterior. Esta zona, de la que aún son visibles algunos restos, forma una amplia curva, manifestada hoy en día por el trazado de la carretera, y comprendía ocho torres incluyendo la llamada del "espolón" en el ángulo de giro que estaban todas terminadas al igual que los paños (14).

Después de la puerta de Jadraque la muralla tenía ocho torres concluidas, aunque cinco de ellas habian sido derribadas en 1495 y a continuación de éstas toda la obra está sin terminar en esta fecha de 11 de octubre de 1496. El sector comprende un total, aparte de las mencionadas, de seis torres hasta la puerta de Guadalajara y la muralla torcía en ángulo recto aproximadamente detrás de la primera manzana de casas situadas junto al Palacio. Esta puerta, que cambia también su ubicación (15) y ségún el documento baja de lugạ, debió estar situada en un ángulo de la plaza y casi seguro donde actualmente se accede a la villa desde la carretera. La cerca continuaba acomodándose al terreno y subiendo hacia el castillo por la calle del Olivar en cuyo extremo estaba la puerta de San Sebastián; después de ésta aún subían por el "lomo" del cerro

13.- En el documento fechado el 11 de octubre de 1496 se hace mención especial al refuerzo de los taludes con las indicaciones: "de cinco pies y medio según el medio pie que su sennoria mandó acrecentar" o "no gozan del dicho medio pie". A.D.M., Secc. Cogolludo, leg. 11, $n^{2} 44$, fols. 1r.-5v. (Doc. $\left.n^{2} 4\right)$.

14. -Cfr. Doc. $n^{2} 4$, fols. $15 r-15 v$.

15. Cfr. Doc. $n^{9} 4$, fols. $15 r-18 \mathrm{v}$. 
siete torres hasta alcanzar la coracha (16). Todo este sector se terminó en los años sucesivos al igual que la coracha, barrera con adarve y una torre en el extremo sobre el barranco de San Agustín, que partía de la fortaleza (17) y defendía la zona de huertas (18) situadas entre ella y la muralla. Las puertas de Jadraque y Medinaceli se concluyeron en 1503 (19), pero desconocemos la fecha en que ocurrió otro tanto con la de Guadalajara (Lám. 1).

La muralla debió asemejarse a las de su época. Tenía un perímetro aproximado de un kilometro y medio y una superficie que rondaba las diez y seis hectáreas. Los paños eran todos de mampostería ordinaria y tenían un talud de cinco pies y medio de grueso, disminuyendo en el pretil medio pie. La altura media de éstos se aproximaría sin almenas a los seis metros. No sabemos con exactitud si todos los tramos tenían adarve o camino de ronda pero si existían desde la puerta de Medinaceli hasta la de Jadraque. Las torres, de mampostería ordinaria y reforzadas con sillares en los ángulos al parecer, tendrian unos ocho o nueve metros de altura y según las descripciones eran cuadradas con escalera interior y cubiertas con bóveda. La longitud de los paños entre las torres oscila entre veintidos metros desde el castillo hasta la puerta de Jadraque, veintiocho entre ésta y la puerta de Guadalajara y veintidos desde la última hasta el castillo. En la actualidad se conservan algunos paños y torres detrás de Palacio y pueden verse restos en la curva de la carretera de Atienza, según hemos marcado en el plano (Vid. Lámina 1, 2 y 3).

Las puertas, según la documentación, estaban flanqueadas por dos torres cuadradas, tenían una escalera interior con bóveda desde la que se subía al adarve, por encima de la puerta nacían otras escaleras exteriores, ocultas tras antepechos, para subir hasta las torres altas. Las puertas eran todas de sillares de cantería que proceden, al menos algunos, de Puente Roderos (20). A fines

16. - Cfr. Doc. $n^{2} 4$, fols. 17r-21v. La puerta de San Sebastián ya estaba construida en 1495 según el Doc. 3 fol. $2 v$ donde se recoge: "mando su sennoría abrir un çimiento vn pedaço de la puerta de Sant Sebastian para endereçar la çerca... Pedro de Foios que lo abrió e gasto setecientos e treynta e çinco maravedis".

17.-A.D.M. Sec. Cogolludo, leg. $11 n^{\circ}$ 48, fols. 2v-3r. Cogolludo, 9 de noviembre de 1505 (Doc. n'5).

18.-LOPEZ GUTIERREZ A.J.: Documentación Señorial y Concejil, p. 81, doc. $n^{\circ} 25$. El àno 1517 se citan unas huertas donadas por el Duque D. Luis de la Cerda a Martin de Alcaraz: "a raiz de la coracha que viene dada desde la cerca della a dar a la caba de la fortaleza... y otro pedazo que esta junto a ésta, que vaxa desde el adarve de la coracha hasta dar en el corral de Anton del Olmo".

19. - Cfr. Doc. nं 5, fols. 2v-3v.

20.-Crr. Doc. n' 4 , fols. 8r-8v y $11 v-13 r$; Doc. $n^{2} 5$ fols. $3 r-3 v$. 
del siglo pasado aún se conservaban algunas de éstas según las descripciones contradictorias de D. José María Quadrado y el Sr. Catalina García. El primero las describe así: cuadradas torres de sillería flanquean sus magníficas puertas de arco semicircular, coronadas con modillones, sobre los cuales asentaban los adarves, ya casi derruidos" (21); y el segundo nos habla de: "buenas fortificaciones consistentes en el castillo y su muro torreado, con dos puertas de arco ojival que han desaparecido en los últimos años para dar más amplio ingreso a la carretera" (22). No obstante a tenor de estas descripciones y por la documentación no creemos que fueran muy diferentes a las de Palazuelos, aunque aquí las torres son semicirculares, o a la puerta de Hita, mandada construir por el primer marqués de Santillana en 1445 y demolida hace poco más de cuarenta años (23).

Las obras realizadas en la cerca y castillo de Cogolludo durante el mandato de los dos primeros duques de Medinaceli y a tenor de los datos que nos suministran la documentación que aportamos asciende a la cantidad de 3.359.165, 5 maravedís, si bien por las diferencias que se van acumulando al ir arrastrando las cuentas de un folio a otro o al ir pasando las cantidades a los correspondientes parágrafos existe una diferencia de 79.892, 94 maravedís con 2,41 cornados en contra de dicha cantidad. Por ellos el valor real que costaron las obras allí realizadas fue el de 3.279.271,56 maravedís con 3, 59 cornados, y no el anteriormente indicado (24).

En la actualidad Cogolludo presenta la clásica fisonomía de las ciudades señoriales con un caserío apenas modificado desde el siglo XVI. En 1557 el duque $\mathrm{D}$. Juan de la Cerda fundó a las afueras de la villa, pero no lejos de ella un monasterio de franciscanos bajo la advocación de San Pedro, que pertenecía a la provincia de San Diego, y cuyas obras aún continuaban en 1581 (25). Este convento, más conocido por San Antonio debido a la imagen que había en su portada, generó un arrabal en la parte occidental de la villa entre su

21.-QUADRADO, J.M.: Castilla la Nueva, Barcelona, D. Cortezo, 1885, t.l p. 156.

22.-CATALINA GARCIA, J.: Relaccionesp. 36.

23.-Reproducidas por LAYNA SERPANO, F.: La provincia de Guadalajara, Madrid, Hanser y Menet1948, p. 78; GOMEZ MORENOE: A.E.A.A. p. 17-18.

24.-Para la comprobación en la suma de las cantidades de los documentos $3,4,5$ y 6 vease la edición de los documentos y aparato critico de los mismos de LOPEZ GUTIERREZ, A. J.: "Cogolludo, un sefiorio castellano de la Baja Edad Media", (en prensa).

25.-Fra. Fco. GONZAGA: De origine seraphica Franciscae eiusdae progressibus, de Regularis observantiae institutione, forma administrationis ac legibus, admirabilis que eius propagatione, Roma (D. Basa), 1587, t. II p. 634. 
compás y la puerta de la localidad que comprendía la llamada calle de San Francisco como prolongación del camino de Aleas, la calle del Olivar que sube por el cerro hasta enlazar con el castillo, y por la parte occidental comunicaba el compás con la puerta de Guadalajara por una callejuela. El convento según el Catastro del Marqués de la Ensenada estaba dentro de los muros (26) de la villa en 1651, aunque desconocemos la fecha exacta de esta ampliación de la muralla y su alcance. El plano de Cogolludo de 1895, conservado en el Instituto Geográfico Nacional, no aporta ningún dato al respecto en sus defensas y fortaleza muy deterioradas ambas después de la Guerra de la Independencia, razón por la que creemos fueron omitidas en él.

Hasta hace pocos años no se ha rebasado el límite de esta villa respecto a los que tenía a fines del siglo XVI y principios del XVIII. El crecimiento se ha realizado al otro lado de la carretera de Atienza y recientemente una urbanización ocupa la parte del cerro entre la antigua coracha y las ruinas del convento franciscano.

\section{Las obras realizadas en el castillo del Cogolludo.}

A principios del siglo XVI el II Duque de Medinaceli, D. Juan de la Cerda, llevó a cabo un plan de renovación de sus castillos de Somaen, Arcos, Montuega y Cihuela. En este último, Lorenzo Vázquez y Pedro de Piedrahita tasaron en 1502 las obras realizadas, por los canteros García de Liebana y Juan López (27). Las obras realizadas en el castillo de Cogolludo en 1503 y 1505 no suelen incluirse en esta empresa ducal que a diferencia de las anteriores tienen un carácter defensivo. Según se desprende por los documentos consultados consistían en reforzar la barbacana del castillo y realizar en ella una puerta de recodo. A su vez se reforzaron la puerta interior del castillo y la barbacana, se construyó un arsenal y se levantó un muro que unía las dos torres meridionales. También en el muro de la coracha se efectuaron obras para la instalación de artillería y armas arr jadizas.

En 1503 Lorenzo Vázquez y Pedro de Piedrahita tasaron las obras realizadas por Andrés de Hoyos y García de Liebana en el castillo de

26.-En el Catastro del Marqués de la Ensenada se indica: "Respuesta 39: Comunidades religiosas, la una dentro de los muros y de Padres. Misioneros de la Orden de Nuestro Padre San Francisco de la regula de observancia". Vid. ARCHIVO HISTORICO PROVINCIAL DE GUADALAWARA, leg. 495, fol. $67 \mathrm{v}$.

27.-COOPER Ed.: Castillos sefioniales de Castilla, siglos XV-XM. Madrid, Fundación Universitaria Espafiola, 1983 t.l p. 37 y 608 not. 19 (Castillos Sefioriales). 
Cogolludo que consistieron en reforzar la barrera de la fortaleza con mampostería, construcción de una cámara en el interior.

"guardar los tiros de polvora grandes, las lombradas, e pasamoros e todos los tiros e cuelebrinas e espingardas e vallestas fuertes e todos los otros tiros".

También se concluyen todas las obras de la coracha y se colocan encima de su puerta "dos troneras $e$ tres saeteras" y se levanta una escalera que comunica esta zona defensiva con la fortaleza (28).

Dos años más tarde Cristobal de Adonza es quien tasó las obras de García de Liebana que completaban las anteriores con:

"un panno de baluarte que está dentro de la barrera que es junto a la puerta de medio que viene junto con la puerta del dicho baluarte... el arco de dicha portada"

y una escalera para subir al andén. También y frente a la puerta de la fortaleza se levantó un paño y otro que iban desde la torre del homenaje hasta la de la campana (29) que suponemos más cercana a la iglesia de Santa María.

La presencia de todos estos maestros en Cogolludo evidencia una planificación en las obras de los dos primeros duques de Medinaceli, no sólo por el carácter de las construcciones que se realizaron sino también por la presencia de los tasadores y algunos artífices como Cristobal de Adonza que está al servicio de ambos y también años más tarde de algún otro miembro de la familia Mendoza.

Relación de maestros de obra, tasadores y artífices de la muralla y obras del castillo llevadas a cabo por los dos primeros duques de Medinaceli.

ADONZA, Cristobal de: maestro de cantería. Las relaciones familiares entre los duques nos hacen suponer que el "Cristobal de Adonça, vecino de la ciudad de Toledo" documentado en Cogolludo en 1494-1495 1505 es el mismo que en 1509 actúa como tasador del II Conde de Tendilla, D. Inigo López de Mendoza, junto a Lorenzo Vázquez en la catedral de Granada y

28.-Cir. Doc. $n^{2} 5$ fols. $1 r-3$ r.

29.-A.D.M. Sec. Cogolludo, leg. $11 n^{0} 48$, fols. 1v-2v. Cogolludo, 9 Diciembre 1505 (Doc. $n^{0} 6$ ). 
que posteriormente realiza la iglesia parroquial de Mondejar en 1516. Con anterioridad se sabe que en 1500 trabajó junto a Juan Gil en la portada de la catedral de Sigüenza (30).

En la documentación de Cogolludo se le abonan los pagos de la cerca. En 1494 realiza obras en la zona de la puerta de Guadalajara que fueron derribadas un año después. En 1496 se le pagan unos derribos para: "abajar la puerta de Guadalajara a donde agora está" así como lo que tiene construído en este sector de la puerta con los paños anteriores y posteriores a ésta. En 1505 actúa de tasador para las obras realizadas por García de Liebana en la fortaleza (31).

BALLESTEROS, Juan de: Vid, Vallesteros, Juan de.

CARAZA, Rodrigo de: maestro de cantería. Tasador por parte del duque de Medinaceli en 1496 (32).

CUBILlaS, Pedro de: su cuadrilla trabaja en dos sectores de la cerca: en el postigo de Arbancón donde hace unos paños y una torre, y en el tramo posterior a la torre del espolón donde levanta dos torres con sus correspondientes lienzos de muralla (33).

FOIO o FOIOS, Andrés de: la cuadrilla de este Andrés de Foio o Hoyos está documentada en Cogolludo desde 1496 hasta 1503 (34). Realiza la puerta de Medinaceli, dos torres con sus paños correspondientes encima de la puerta de San Sebastián, un talud de sillería labrado a pico en la esquina de la muralla que situaríamos entre la fortaleza y la iglesia de Santa María; un paño de mampostería en la "barrera" del castillo que debió consistir en un reforzamiento de la barbacana. Dentro de la fortaleza hace una escalera para subir a la coracha y una pared en el patio para hacer una camara de arsenal. Finalmente también tiene pagos en la coracha.

30.-GOMEZ MORENO, E: A.E.A.A. p. 24, 27-28 y 246; AZCARATE Y RISTORI J.M.: Castilla La Nueva, Madrid, Ed. Noguer, 1982 T. pp. 216 y 223; MUÑOZ JIMENEZ J.M.: "Consideraciones sobre el gótico arcaizante en la provincia de Guadalajara" en "Arte Gótico Postmedieval" (Simposio Nacional del C.E.HA., Segovia 7-8 junio 1985), Segovia, Caja de Ahorros, 1987 p. 127 ("Consideraciones).

31.-Crr. Doc. $n^{e} 3$, fols. 1r, 2r-2v, 5r-5v y 6r; Doc $n^{2} 2$, fol. 1r; doc. $n^{2} 4$ fol. $21 v$; doc. $n^{0} 6$ fol. ir y $3 r$.

32. -Cir. Doc. ñ 4, fol. 1r.

33. Cfr. Doc. $n^{0} 4$, fol. 3r-3v, 9v-10v.

34. -Cfr. Doc. $N^{2} 4$, fols. 7v-8v, 20r; Doc. $n^{2} 5$ fols $1 r-1 v$. 
FOIO el mozo, Juan de: documentado en 1496 (35) realiza los paños y una torre y media debajo del postigo de Arbancón. También se le abona una torre y los paños correspondientes encima de la puerta de San Sebastián.

FOIOS, Pedro de: forma cuadrilla con Juan de Veranga (36).

FOIOS, Sancho de: trabaja en 1496 bajo la iglesia de Santa María (37) donde realiza los paños y una torre. También construye la torre del espolón junto con otra en el mismo ángulo de la muralla con sus paños correspondientes.

GORMAZ, Yuca de: moro, tasador y mediador en 1494 de la cerca para derribar (38).

GUEMES, Pedro de: maestro de cantería. Midió en 1495 junto a Pedro de Piedrahita los derribos de la cerca (39).

LIEBANA, García de: maestro de cantería. Aunque aparece documentado como tasador en la cerca en 1495-1496, también realiza las obras más importantes de la fortaleza de Cogolludo y concluye las puertas de la muralla así como algunas de sus partes (40).

En la puerta de Jadraque realiza la torre, media puerta y los paños que unen a ésta con el sector de detrás de la huerta (Palacio). Delante de este Palacio construye tres torres con sus paños en 1496 y en el mismo año se le abonan los derribos de las obras efectuadas en este sector dos años antes. En el sector de la puerta de Guadalajara derriba también detrás de las casas nuevas de la plaza en 1496. En 1503 efectúa obras en la coracha consistentes en tapias, dos troneras y saeteras en la fuente de la puerta de la coracha. Termina la puerta de Medinaceli y Jadraque realizando las escaleras y un lienzo del lomo.

El dicho García de Liebana aparece también nombrado como maestro de cantería y vecino de la dicha villa en 1503 y 1505 . En la misma época hay referencia a un García de Liebana, albañil, trabajando para el Duque de Medinaceli en el castillo de Somaen, y también otro con el mismo nombre

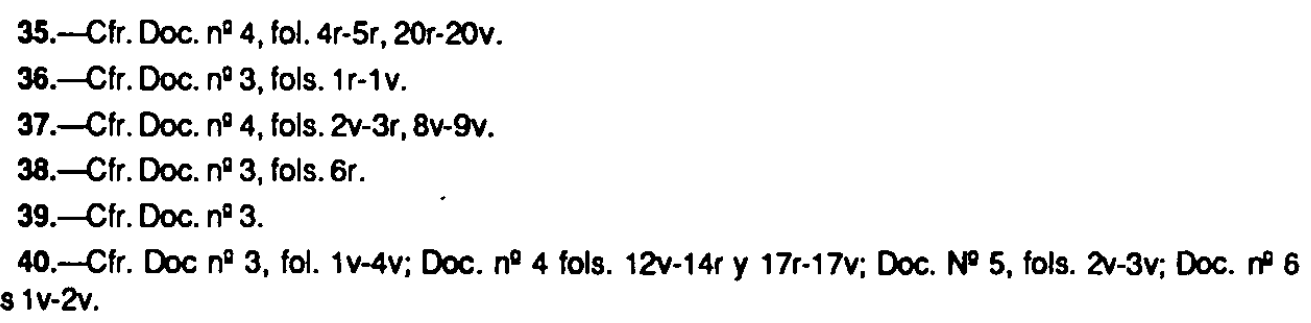


pero como maestro de cantería en el castillo de Cihuela (41), ambos propiedad del duque de Medinaceli y renovados en la misma época que el de Cogolludo a principios del siglo XVI.

LOPEZ, Juan: su cuadrilla está documentada en Cogolludo en 1495 y 1496 cuando se le pagan unos derribos y levanta cuatro torres con sus paños detrás del Palacio (42). No sabemos si se trata de Juan López, cantero, documentado en el castillo de Cihuela (43).

PENNA (PEÑA), Pedro de: cuadrilla que bajo sus órdenes está documentada en Cogolludo en 1495 y 1496 trabajando en las tres torres con sus correspondientes paños que unen con la puerta de Jadraque en el lado oriental de la cerca (44).

PIEDRAHITA, Pedro de: maestro de cantería, documentado en Cogolludo como tasador desde 1495 hasta 1503 (45).

Un maestro cantero del mismo nombre tasa junto a Lorenzo Vázquez en 1502 otras obras del Duque de Medinaceli, y también trabajó para la familia Mendoza en el Palacio del Infantado de Guadalajara donde realizó las caballerizas, la cimentación de las columnas de la galería y sus estribos laterales así como la caja de la escalera (46).

PUENTE, Juan de la: su cuadrilla realiza el postigo de Arbancón con una torre de esta puerta y los tramos de la muralla anteriores y posteriores a esta en 1496. En este año también se le abonan los derribos de los paños realizados en 1494 y 1496 que unían con la puerta de Guadalajara y en el mismo sector también unos paños y tres torres (47).

PEREZ DE FOIO, Juan: documentado en Cogolludo en 1495 y 1496, su cuadrilla realiza los paños y una torre debajo del postigo de Arbancón (48). En la puerta de San Sebastián también se le abonan primero unos derribos y más tarde una torre y dos tramos de paños.

41.-COOPER: Castillos senoriales, p. 37,47 y 608.

42. -Cfr. Doc. $n^{2} 3$, fol. 1 r; Doc. $n^{2} 4$ fols. $15 \mathrm{v}-17 \mathrm{r}$.

43.-COOPER: Castillos senoriales, p. 47.

44.-Cfr. Doc. n 4, fols. 14v-15v.

45.-Cir. Doc. $n^{0} 3$, fols 1 r y $6 r$; Doc. $n^{2} 4$ fols. 1 r y $21 v$; Doc. $n^{2} 5$, fols. 1 r y $3 v$.

46.- LAYNA SERRANO, Fco.: El palacio del Infantado: Madrid, Hauser y Menet, 1941 p. 73; COOPER Ibidem not 43.

47. -Cfr. Doc. $n^{2} 3$, tols. $1 v$ y $5 r$; Doc. ne 4 , fols. 5v-6r, 7ry $17 v-18 v$.

48. -Cfr. Doc. $n^{0} 3$ fol. $3 r$; Doc. $n^{0} 4$ fol. $6 \mathrm{v}$. 
VALLESTEROS, Juan de: realizó en 1496 los paños y una torre detrás de Santa María; dos torres y paños en el cabo de la torre de la coracha. En 1494 realizó obras en la torre de la coracha que fueron derribadas dos años más tarde (49).

VAZQUEZ, Lorenzo: maestro de cantería. La vinculación de Lorenzo Vázquez de Segovia a Cogolludo fue apuntada por vez primera por D. Manuel Gómez Moreno al estudiar las relaciones de este artista con otros miembros de la familia Mendoza. También el mismo menciona la tasación de las obras del castillo de Cihuela en 1502 (50). Sin embargo hasta el presente no había constancia documental de que el maestro hubiera estado en la villa alcarreña. Sin duda alguna, la tasación de 1503 es un testimonio más que prueba la atribución del Palacio de Cogolludo a este maestro (51).

Es posible incluso que pudieramos atribuirle la disposición de la nueva muralla por los cambios efectuados en la zona del Palacio y en la plaza entre 1494 y 1496, así como no sería de extrañar que en cierta medida su opinión fuese tenida en cuenta para las obras realizadas en el castillo.

Los dos documentos que revelan el estado de la muralla en 1496 muestran como el Palacio debía estar ya muy avanzado dos años antes, lo cual nos hace suponer que ciertamente su cronología podría precisarse más: en 1494 debía estar concluida la parte vivienda faltando por completar los jardines, a tenor de los derribos.

VELEZ, Juan de: maestro de cantería, realiza en 1496 (52) una torre y los paños situados en la parte más alta del postigo de Arbancón. Delante de. la puerta de Guadalajara se le abonan unas obras hechas en 1495 cuyos derribos junto con los cimientos se le pagan un año más tarde. También en 1496 realiza unos derribos para bajar la puerta de Guadalajara y para que los paños vinieran derechos y salieran más afuera de donde estaban. En octubre del mismo año estaba realizando unos lienzos de muralla y tres torres. Por el documento de 1503 se desprende que un año antes realizó en Cogolludo obras en la muralla en el sector que subía por el lomo hasta la coracha.

El documento de 1505 cita como tasador a Juan Velez, maestro de cantería, vecino de Praves y más adelante menciona a otro Juan Velez el

49. -Cfr. Doc. $n^{2} 3$, fols, 3v-4r; Doc. $n^{2} 4$, fols. 2r, 21r-21v.

50.-Ibidem Not. 27.

51.-Cfr. Doc. $n^{\circ} 5$, fols. 1 r y $3 v$.

52.-Cir. Doc. $n^{0} 3$, fols.. 2v-3r y 6r; Doc $n^{9} 4$ fols. $5 r$ y 19r-19v; Doc. $n^{2} 6$, fol. ir y $3 v$. 
viejo, e Rodríguez Vélez, vecinos de Argennos, habitantes de estas dichas villas (53), aunque no podemos precisar cual de estos dos es el que efectúa las obras citadas.

VEGA, Juan de: su cuadrilla realiza en Cogolludo dos paños y dos torres que unían con la puerta de Jadraque (54). En esta misma puerta hace en 1496 una torre y media.

VERANGA, Juan de: esta cuadrilla trabaja en Cogolludo en 1496 junto a Pedro de Foio en una torre que junta con la fortaleza y también realizan unos paños en la misma zona. En el lomo de la villa realiza también otros paños y una torre. Su cuadrilla recibe en el mismo años unos pagos por el derribo de tapias y abrir cimientos en el lomo (55).

\section{Notas Paleográficas.}

Nuestro análisis de las fuentes documentales se refiere a los cinco documentos originales cuatro inéditos que adjuntamos en el regesto documental (56). Todos ellos se enmarcan dentro del periodo que denominamos como "el ciclo de las escrituras góticas" por cuanto nos presenta una variedad de grafías góticas que van desde la semigótica (57) a la cortesana (58). Ambas son minúsculas pero con notorias diferencias. Así mientras que la semigótica presenta un ductus lento que va a producir unos rasgos caligráficos en las formas de sus letras; la cortesana nos muestra un ductus mucho más rápido que se refleja en la deformación de los trazos de ciertas letras. Ambos tipos de escritura conviven en un mismo texto, como ocurre en el caso del doc. $\mathrm{n}^{\mathrm{a}} \mathbf{2}$, que contiene semigótica para el texto y cortesana en las suscripciones.

El soporte gráfico se encuentra representado por el pergamino y el papel. En pergamino aparece redactado un solo documento, aquel que se refiere a la permuta que va a vincular Cogolludo a la Casa de Medinaceli (59). Permuta que además nos presenta la peculiaridad de mostramos la escritura más cuidada como es el caso de la minúscula caligráfica o semigótica. En papel tenemos

53.-Cfr. Doc. $n^{2} 4$, fols. 10v-12v; Doc, no6 fols. 1 ry $2 v$.

54.-Cfr. Doc. $n^{2} 3$, fol. 3v; Doc. $n^{9} 4$, fols. 1r-1v, 20v-21r.

55.-Cfr. Doc. $n^{2} 3$ fols $1 r-1 v, 3 v ;$ Doc. $n^{2} 4$, fol. $1 r-1 v$.

56.-Doc. 2,3,4, 5 y 6. De ellos cuatro son inéditos: $n^{0} 3,4,5$ y 6 . Para la edición, transcripción y notas criticas Vid. LOPEZ GUTIERREZ. A. Ibidem nota $n^{\circ} 24$.

57.-Ctr. Doc. $n^{2} 2$, salvo las suscripciones.

58.-Cfr. Docs. $n^{\mathfrak{Q}} 3,4,5$ y 6 , amén de las suscripciones del doc. $n^{\mathfrak{Q}} 2$.

59.-Vid. Doc. $n^{2} 2$. 
el resto de los documentos (60). Su forma le viene conferida a partir del doblez del pliego constituyendo así dos hojas que son utilizadas de forma más o menos general por el recto y por el vuelto:

$E$ van escriptos en doze planas de papel de pliego entero (61).

Escrevítodas estas medidas e tasaciones en estas cinco planas de pliego entero (62).

Incluso para la denominación del doc. $\mathrm{n}^{\mathrm{a}} 4$ las propias fuentes emplean la denominación de libro:

El qual libro va escripto en veinte e vna fojas de pliego de papel entero, con aquesta en que va mi signo (63).

Presentan un papel verjurado con filigrana que representa una flor con seis pétalos (64), y mano con estrella de cinco puntas (65).

El estado de conservación de todos ellos es bastante aceptable y su tintada presenta un matiz ocre oscuro, patente en cada uno de los documentos.

\section{Notas Diplomáticas}

En cuanto a la tradición de estos documentos cinco son originales (66) y el restante se trata de una copia (67). Por otra parte, con relación al lugar de elaboración de estos domuentos: uno posiblemente lo fuera en la oficina de expedición de documentos de la Orden de Calatrava de la que desgraciadamente pocas noticias tenemos (68); otro, nos referimos al documento señorial, nos presenta una letra enormemente cuidada y unas formas documentales revestidas de gran solemnidad. Todo ello pensamos tenemos que relacionarlo con la presencia en el documento de un personaje como Fernán Alvarez de Toledo, oidor e referendario del rey y su secretario y que muy probablemente pueda explicarnos las particularidades que desde el punto de vista diplomático nos presenta este documento (69); y los cuatro documentos restantes fueron

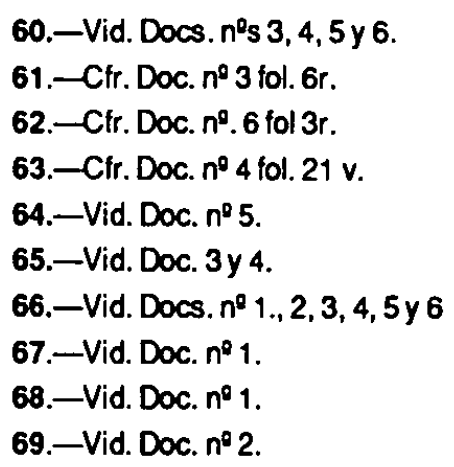


elaborados en oficinas notariales: en concreto ante la fides pública de Esteban de Aleas, refiriéndose todos ellos a la medida y tasación realizada en la muralla de Cogolludo y su castillo (70). Veamos el proceso de elaboración de estos cuatro últimos documentos.

Para el estudio de la génesis documental de estos cuatro documentos notariales no contamos con estudio detallados como ocurre en la Corona de Aragón (71), sin embargo estas dificultades previas vamos a intentar obviarlas a través de los datos que nos suministran los propios documentos, amén de las noticias contenidas en las fuentes legales de la época.

Por lo que respecta a la actio documental, se realizaba ante el escribano que a la postre va a ser la persona que con la aposición de su signo le aporta la fides publica al documento expedido. Así pués, la presencia del escribano resultaba imprescindible para que diera fe de todo cuanto acontecía, máxime en este tipo de negocios, relacionados directamente con la Hacienda del Señorio, en los que se dilucida ni más ni menos que la medida y tasación de una serie de obras que se han llevado a cabo en la cerca y castilo de la villa de Cogolludo.

Junto al escribano figuran unos personajes que se presentan ante él, aduciendo su nombre, oficio o cargo y los motivos que condicionan su presencia. A continuación pensamos que el escribano iba tomando una serie de notas que con posterioridad iba pasando a su registro. Aquí nos encontramos con uno de los problemas que desgracidamente se quedarán sin dilucidar cuál es si la redacción de la nota se efectuaba aparte del registro 0 bien si ésta se plasmaba directamente sobre él. Como deciamos no podemos aportar más luz al tema con los escasos datos que manejamos.

Igualmente también podemos lanzar como hipótesis la posible presencia de una serie de testigos para presenciar la actio y otros que lo estarian delante de la conscriptio documental, al menos así lo entendemos cuando en los documentos se recoge:

Testigos que fueron presentes llamados y rogados para testimoniar, asi para ver medir la çerca como para ver conçertar este libro con mi registro: Cristóval de Adonça, vezino de la çiudad de Toledo e Juan García, vezino de... e García de Liévana, vezino desta dicha villa; $e$

70. -Vid. Docs. $n^{0} 3,4,5$ y 6.

71. -Nos referimos al trabajo de M" Teresa FERRER Y MALLOL: La redació de Rinstrument notarial a Catalunya. Cedulas, manuals, llibres incartes en "E.H.D.A.P." IV (1979) pp. 29-192. 
para ver concertar el dicho con el dicho registro: Luís García, notario, e Juan de Aleas e Martín de la Guerra, vezinos de la dicha villa (72).

El inicio de la conscriptio documental tenía lugar mediante una petitio al escribano para que consignara el acto por escrito. Petitio, que reviste forma de mandato en los documentos $n^{2} 4$ y $5^{\circ}$ :

E mandaron a mi, el escriuano, que así, asi (sic) a su senoría commo a los oficiales signada (73).

$E$ así fechas las dichas medidas y tasaciones de suso dichas...mandaron a mi, el escriuano, que lo diese signado para lo presentar ante su sennoría e ante su contador. (74).

mientras que en el documento $\mathrm{n}^{2} 6$ reviste forma de petitio:

$E$ así fecha la dicha medida y tasación por los dichos Cristóval de Adonça e Juan Vélez de Praves. . el dicho García de Lievana pidiólo por testimonio signado para lo presentar a sus sennorías (75).

Una vez que la actio ha sido consignada en el documento, se menciona a los testigos y ciertos actos que han acontecido entre la actio y la finalización de la conscriptio, cúal es la contropatio con lo contenido en el registro:

E para ver conçertar el dicho libro con el dicho registro (76).

Testigos que fueron presentes llamados y rogados para teśtigos, para ver sacar e conçertar esta relación e tasación de lo derriuado que se derriuó (77).

Por último, tenía lugar el otorgamiento de los intervinientes y testigos que desde finales del siglo XV comienzan a poner su firma en el libro registro:

De lo qual firmó el dicho Cristobal de Adonça por él e por Juan Vélez, de su conpanero, en el registro de mi, el escriuano (78).

Por lo que respecta a sus formas documentales, el documento de Ordenes Militares, sę trata de una donación a favor de Iñigo López de Orozco.

\footnotetext{
72. -Cfr. Doc. $n^{2} 4$, fol. $21 \mathrm{v}$.

73.-Ibidem.

74. -Cfr. Doc. ne 5, fol. $3 v$.

75. - Cfr. Doc. $n^{0} 6$, fol. $2 v$

76. - Cfr. Doc. $n^{0} 4$, fol. 21 v.

77.-lbidem.

78. -Cfr. Doc. $n^{0} 6$, fol. 3r.
} 
Donación que reviste la forma de documento sinalagmático: mandamos facer dos cartas partidas por a.b.c, amas en un tenor (79), y en él se hace constar unas puntualizaciones precisas y concretas a cerca de la referida donación.

Consta de notificación, intitulación, expositivo, dirección, dispositivo con una serie de puntualizaciones de tipo jurídico, claúsulas, anuncio de validación y data. No poseemos dato alguno acerca del autor material de documento.

El documento señorial se trata de una carta de permuta que desde el punto de vista del marco legal del gobierno del señorío se enmarca dentro de aquellos documentos que establecen relaciones entre dos señores (80). El formulario de la permuta, heredado de la tradición hispano-visigoda, consta de: notificación, intitulación, dispositivo, claúsulas, anuncio de validación, datas y suscripciones.

Los cuatro docuementos notariales revisten forma de actas presentando su disposición usual. A estos documentos también podríamos denominarles como testimonios notariales. Todos ellos se encuentran relacionados con la Hacienda del Señorío por el pago de las obras realizadas en la cerca y en el castillo de la villa (81).

\section{REGESTO DOCUMENTAL}

$$
\text { 1.- }
$$

1335, abril 19

Garci López, maestre de la Orden de Calatrava, concede a Iñigo López de Orozco, alcaide de Escalona, el castillo y villa de Cogolludo para que disfrute de ella durante los días de su vida con una serie de condiciones, entre ella las de adobar y reparar la dicha villa y castillo.

B.-A.H. Colección Salazar y Castro, I-39, fols. 86-87

C.-A.H. Colección Salazar y Castro, D-10, fols 51-51 v.

CIT.-J. Catalina. Relaciones, t.II. Pág. 23: A. López. Documentación señorial y concejil, pág. 6.

79. -Vid. Doc. $n^{9} 1$, fol. 87.

80.-Vid.Doc. n' 2.

81. -Vid. Docs. $n^{9} 3,4,5$ y 6 . 
1438, septiembre 12 .

Olmedo

Luís de la Cerda, III conde de Medinaceli, permuta con Fernán Alvarez de Toledo, señor de Valdecorneja, sus lugares de Garganta la Olla, Pasarón y Torremenga por la villa de Cogolludo y el lugar de Loranca.

A.-A.D.M. Sec. Cogolludo, leg. 11, $\mathrm{n}^{\mathbf{2}} 36$. Pergamino, cuaderno de seis hojas, de las que, ocupa cuatro y media, y dos guardas; $300 \times 215 \mathrm{~mm}$; caja de escritura: $220 \times 160 \mathrm{~mm}$; hueco en blanco para inicial ornamentada. Tinta ocre oscura, salvo suscripción del notario y rúbricas en ocre claro. Escritura semigótica para el texto y cortesana en las sucripciones. Buena conservación.

B.-A.D.M. Sec. Cogolludo, leg. 11, n 36 . Traslado efectuado en Medinaceli, el 12 de diciembre de 1706, por Domingo Mateo Galán, escribano de número de la villa.

CIT.-Inventario de los papeles pertenecientes al marquesado de Cogolludo y condado del Puerto de Santa María, Madrid, 1757, fol. 5r. (Inventario I); Inventario del marquesado de Cogolludo, A.D.M. Sec. Cogolludo, leg. 2, n 52, fol. 7 r.-16v., (Inventario II); Boxador, Títulos y fundaciones, fol. 1v. y 4v.; F. Bethencout, $H^{a}$ Genealógica, t.V, pág. 194; J. Catalina, Relaciones, t.II, pág. 27; Highfield, De la Cerda, pág. 496.

EDT.-A. López, Documentación señorial y concejil, pág. 56-65.

\section{3.-}

(1495-1496)

[Cogolludo]

Esteban de Aleas, escribano público de la villa de Cogolludo, da testimonio de la tasación hecha de los paños de muralla de Cogolludo que fueron derribados por orden de Luis de la Cerda, duque de Medinaceli, para ensanchar el perímetro de la villa y bajar la puerta de Guadalajara durante los años 1495-496.

B.-A.D.M., Sec. Cogolludo, leg. 11, $\mathrm{n}^{2} 44$. Papel, 6 hojas, verjurado; filigrana: mano con estrella de cinco puntas. Tinta ocre oscura. Escritura cortesana. Buena conservación. La copia fue realizada por el propio Esteban de Aleas con posterioridad al 11 de octubre de 1496.

CIT.-Inventario I, fol 7v; Inventario II, fol. 18 r. t 130 r. A. López, Documentación señorial y concejl, pág. 8. 
1496, octubre 11

Cogolludo

Esteban de Aleas, escribano público de la villa de Cogolludo, da testimonio de la medida y tasación hecha por Pedro de Piedrahita y Rodrigo de Caraza, de la muralla de Cogolludo, por encargo de Luis de la Cerda, duque de Medinaceli.

A.-A.D.M., Sec. Cogolludo, leg. 11, $n^{9} 44$, Papel, 21 hojas, verjurado; filigrana: mano con estrella de cinco puntas. Tinta ocre oscura. Escritura cortesana. Buena coservación.

CIT.- fol. 7v.; Inventario II, 18 r. y 130 r. A. López, Documentación señorial y concejil pág. 8 .

\section{5.-}

1503, noviembre, 9.

Cogulludo

Esteban de Aleas, escribano público de la villa de Cogolludo, da testimonio de la medida y tasación hecha por Lorenzo Vázquez y Pedro de Piedrahita de la obra realizada por Andrés de Hoyos en la muralla y en la fortaleza de Cogolludo por orden de Juan de la Cerda, duque de Medinaceli.

A.-A.D.M. Sec. Cogulludo, leg. 11, $n^{9} 48$. Papel, dos pliegos en 4 hojas, la última en blanco, verjurado; filigrana: mano con flor de seis pétalos, Tiṇta ocre oscura. Escritura cortesana. Buena conservación.

CIT.-Inventario I, fol. 8v; A. López, Documentación señorial y concejl, pág. 8.

\section{6.-}

1505, diciembre, 9

Cogulludo

Esteban de Aleas, escribano público de la villa de Cogolludo, da testimonio de la medida y tasación hecha por Cristóbal de Aldonza y Juan Vélez de la obra realizado por García de Liébana en la fortaleza de Cogolludo por orden de Juan de la Cerda, duque de Medinaceli.

A.- A.D.M., Sec. Cogolludo, leg. 11,no 48. Papel, dos pliegos en 4 hojas, la última en blanco verjurado, filigrana inapreciable. Tinta ocre oscura. Escritura cortesana. Buena conservación.

CIT. Inventario I, fol, 8v. A. López, Documentación señorial y concejil, pág. 8. 


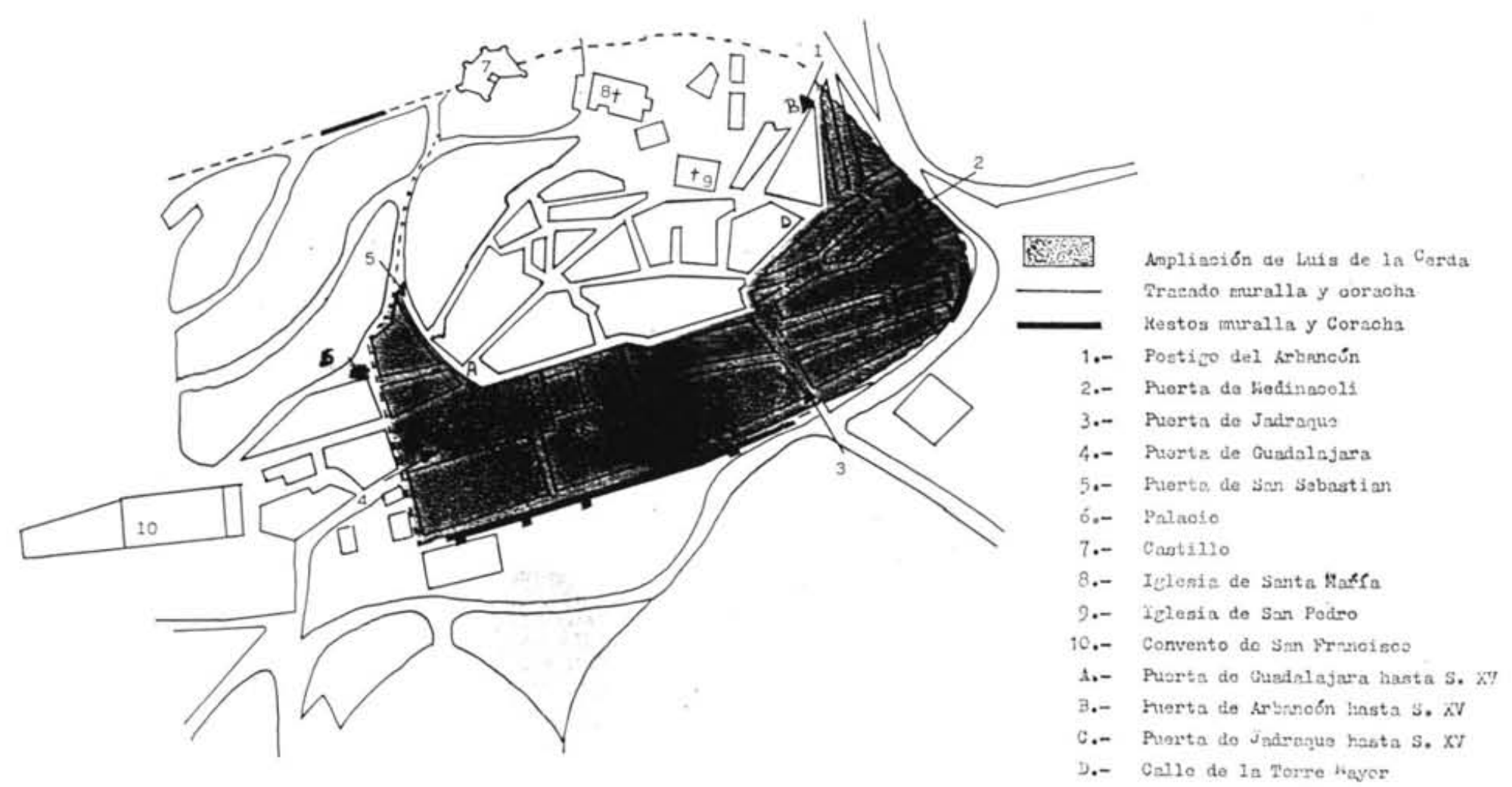

Plano de Cogolludo: Recintos amurallados, puertas y ampliación de D. Luis de la Cerda 


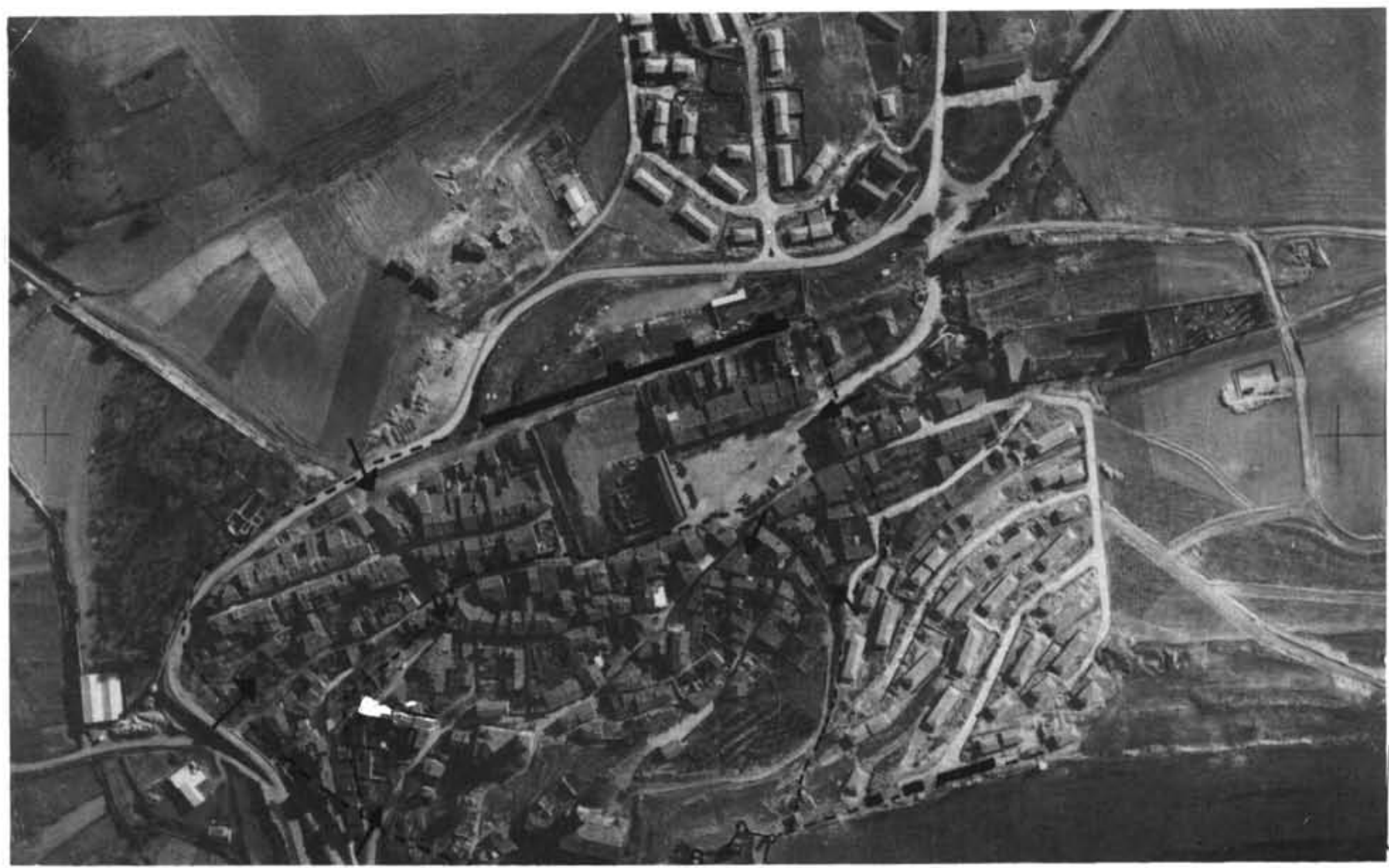

Vista arérea de Cogolludo. Recintos amurallados y puertas 


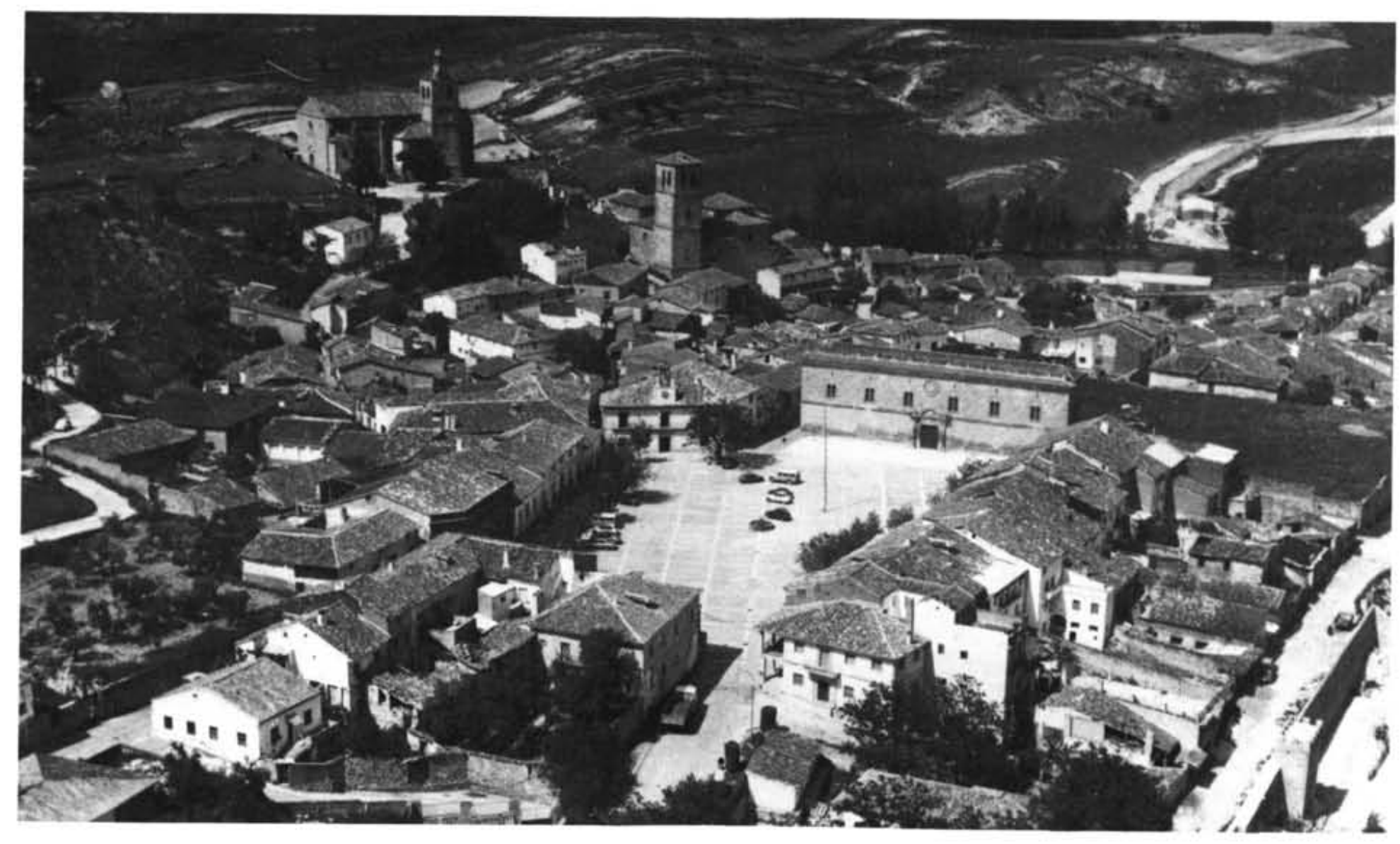

Cogolludo: Plaza Mayor, Palacio y Huerta frente al cual se ubicó la puerta de Guadalajara. En primer término aún se observan restos de las murallas y sector ampliado por D. Luis de la Cerda. 


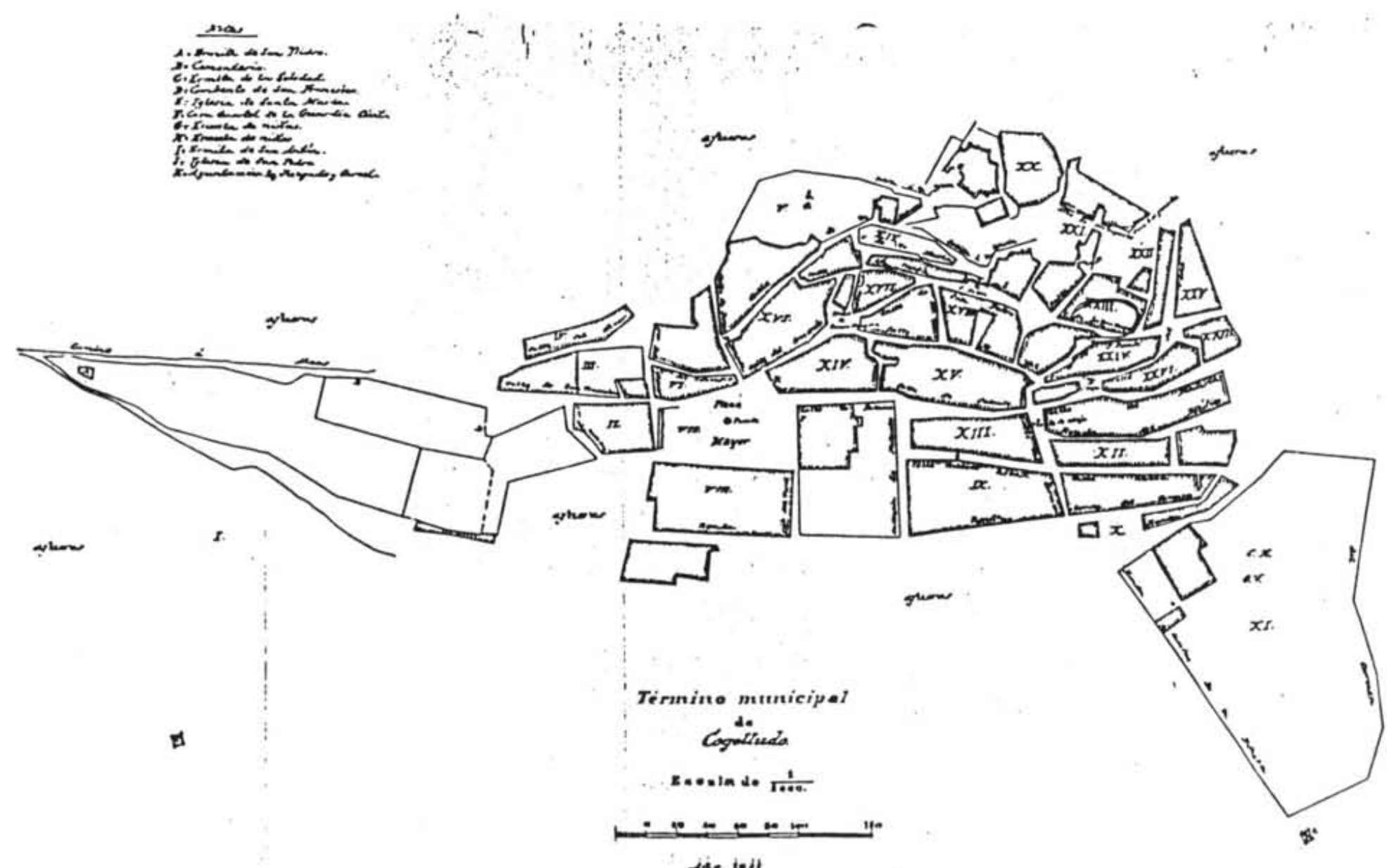

